\title{
Members' Page
}

\section{INAUGURAL MEETING OF ffPS CAMBRIDGE GROUP \\ Friday, 12 November, 6pm}

To be held jointly with the Cambridge Natural History Society, commencing with a wine and cheese buffet supper at $6 \mathrm{pm}$, in the Common Room of the Department of Applied Biology, New Museums Site, Downing Street, Cambridge. At $7.30 \mathrm{pm}$ Sir Peter Scott will talk on Conservation - Where Do We Go From Here? in the Large Lecture Threatre, Department of Zoology, and the Survival film The Hunters of Okavango (30 mins) and The Return of the Fur Seal (30 mins), filmed by Bruce Pearson and Peter Prince and produced by the BBC, will be shown.

\section{London Meetings}

\section{Tuesday, 23 November, $6 \mathrm{pm}$ - Conservation in SE Asia}

Dr David Chivers will give an overview of the conservation of SE Asian primates. Dick Vane-Wright will give an illustrated talk entitled Deforestation Problems for $S E$ Asian Butterflies and Clive Jermy will talk on Botanical Aspects of the Mulu Expedition.

\section{Tuesday, 22 February, 6pm - Joint ffPS/Jersey Wildlife Preservation Trust}

This meeting will be chaired by Lord Craigton with illustrated talks by Jeremy Mallinson, Zoological Director of the JWPT and ffPS Council Member, on Snails to Gorillas, and Dr William Oliver, Research Assistant at JWPT and Chairman of the IUCN Species Survival Commission's Pigs and Peccaries Specialist Group, on Pigs, Peccaries and Babyrusas.

Tuesday, 29 March, 6pm - Expanded Strategies for Endangered Species Dr Norman Myers, author of The Sinking Ark and many other books on controversial conservation issues, will talk on Expanded Strategies for Endangered Species. The Survival film Last Kingdom of the Elephants (50 mins), featuring the Luangwa Valley in Zambia, will be shown.

\section{TICKETS}

At all the above meetings a wine and cheese buffet supper will be served. For 1982 meetings the price remains at $£ 3$ per ticket, but unfortunately we must increase the price to $£ 3.50$ in 1983 . Tickets available from the ffPS office (an $\mathrm{SAE}$ would be appreciated).

\section{Joint Symposium - ffPS/Mammal Society/British Herpetological Society}

Saturday, 27 November - A One-day Symposium on Introductions in the Meeting Rooms of the Zoological Society of London. Details and booking forms available from: Bill Vaughan, Sea Mammal Research Unit, c/o British Antarctic Survey, Madingley Road, Cambridge CB3 OET (an SAE would be appreciated).

\section{ffPS Bookstall}

At the forthcoming meetings we will continue to hold a sale of new and secondhand natural history books. Members are invited to bring any books they wish to sell, with the price pencilled in the front. The Society will take 20 per cent.

\section{Oryx Back Issues}

The Society is in need of any back issue of Oryx, Volume IV and earlier, and would be very grateful if any could be sent to the office. 